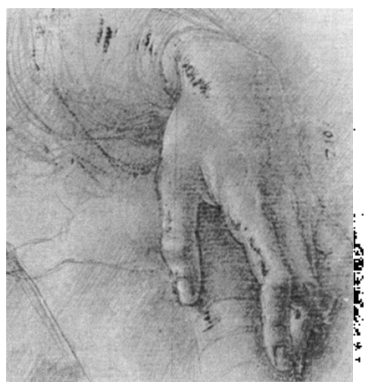

\title{
Trabalho e Subjetividade no Hospital Geral
}

O processo de trabalho no hospital geral é discutido, a partir de um estudo de caso, analisando formas de subjetivação aí produzidas. Apesar do ideal de trabalho em equipe, o processo de trabalho no hospital é analisado como produtor de individualismos e corporativismos que conflitam com este ideal.

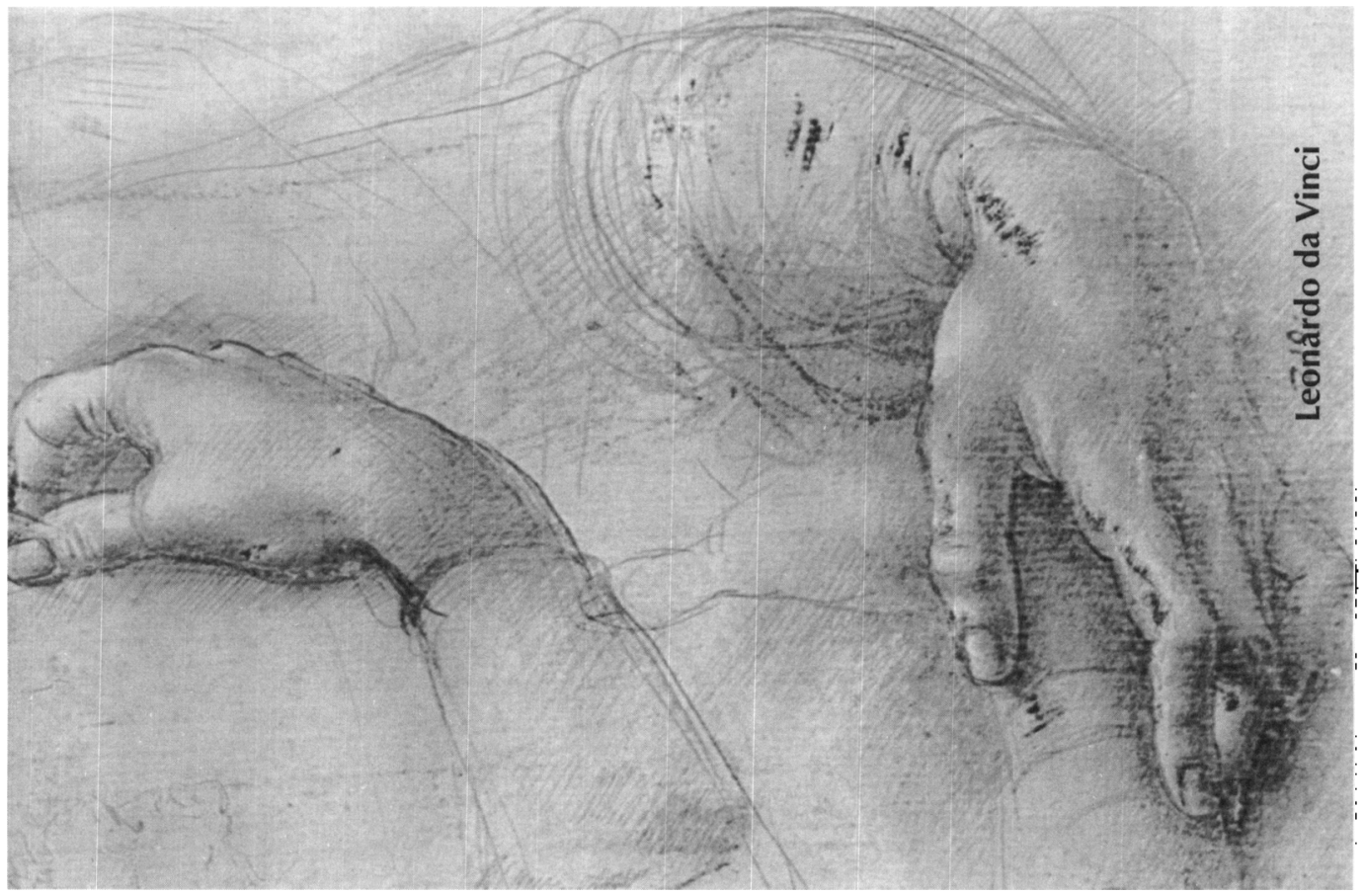

As idéias aqui apresentadas são fruto, principalmente, da pesquisa intitulada Curar Adoecendo, desenvolvida durante os estudos de Mestrado em Saúde Pública, realizados no periodo 19921994. Estão já marcadas por críticas posteriores, reflexōes e desejos produzidos em novos encontros.

O sistema público de saúde no Brasil tem sido apresentado como em "crise", que, no ideograma chinês, aparece como a fusão de duas palavras: perigo e oportunidade. $O$ hospital é habitualmente

Claudia Osorio da Silva

Professora do Departamento de Psicologia do Universidade Federol Fluminense. Doutoranda em Souje Pública na ENSP/FIOCRUZ. considerado como o elo mais importante desse sistema, aparece com freqüência na mídia, recebe muitos investimentos e críticas, assumindo grande importância na formação dos profissionais da área. Esse tem sido o campo empírico de minhas investigaçōes, buscando as possibilidades abertas nos períodos de crise.

Observa-se, já há algum tempo, a existência de insatisfações com o serviço prestado na rede pública de saúde, tanto por parte da clientela quanto dos trabalhadores da área, o que me leva a questionar o que impede mudanças e inovações. Se o hospital está realmente "em crise", esse pode ser um período propício a novas configuraçōes mais satisfatórias, se não, cabe investigar o que de fato ocorre. 
A pesquisa Curar Adoecendo foi produzida como parte de um conjunto de estudos de caso, desenvolvidos por diversos pesquisadores, que tinham em comum seu vínculo com o Programa de Saúde do Trabalhador da Secretaria de Estado de Saúde do Rio de Janeiro (PST/SES), no Hospital Geral de Jacarepaguá.' Desde nossa inserção, como técnicos do PST/SES, observávamos, por fontes diversas e dispersas, que os trabalhadores dos hospitais públicos do Rio de Janeiro vinham sofrendo um intenso desgaste, produzido em sua relação com o trabalho, que se expressava ora em doenças passiviveis de reconhecimento pelo saber médico, ora em desânimo, irritação e outros sinais de desgaste psíquico acentuado. Os estudos encontrados na área de saúde do trabalhador e processo de trabalho hospitalar não respondiam a perguntas que considerávamos fundamentais, entre elas, o que faz com que estas pessoas continuem trabalhando, o que sustenta o hospital público e o bom atendimento em condições reconhecidamente adversas... Supúnhamos que os baixos salários, tão freqüentemente invocados como motivo de desgaste para os trabalhadores, nāo eram explicação suficiente para o quadro observado.

Hoje, a partir desta e outras pesquisas desenvolvidas (Pitta, 1989; Rego, 1993), temos como hipótese, já fundamentada, que o desgaste intenso da saúde do trabalhador do hospital deve-se principalmente à sua impotência frente a uma estrutura hierárquica centralizadora. É a alienação, a impossibilidade de agir criativamente na relação cotidiana de trabalho, os estreitos limites, colocados pela organização do trabalho, ao uso de seu saber, que surge como causa de sofrimento e desgaste. Penso também que o trabalho no hospital produz conflitos entre o ideal, habitualmente suposto, de trabalho solidário em equipe e a organização do trabalho indutora das soluçóes individualizadas, dos corporativismos e da competição acirrada entre especialismos. Os problemas vividos no dia a dia do atendimento aos pacientes e o desgaste dos trabalhadores do hospital se devem à forma assumida historicamente por essa instituição e não apenas a questões conjunturais de falta de pessoal e/ou baixos salários... Estas agravam ou aliviam os impasses sempre existentes, além de terem sua origem naquelas mesmas dinâmicas instituídas (Silva, 1994).

O objeto de minha pesquisa não tem sido a instituição hospitalar como totalidade, mas a teia de encontros e seus efeitos produzidos nessa instituiçâa. Tais encontros se dão entre trabalhadores, entre trabalhadores e clientes e entre pessoas e coisas como, por exemplo, as novas máquinas inventadas e incluídas a cada dia no processo de trabalho.

\section{Segredos e invisibilidades:}

Produzir conhecimento acerca do trabalho em suas relaçóes com os processos de subjetivação em curso no hospital só é possivel trabalhando em parceria com aqueles que tanto sabem sobre tais assuntos trabalhadores em saúde e/ou clientes da rede pública de saúde - aqueles que produzem $\mathrm{e}$ participam cotidianamente de tais processos. As metodologias participativas, em que os objetos da investigaçăo são, simultaneamente, sujeitos dessa mesma investigação, são as que se impõem nos estudos acerca do trabalho, na sua relaçāo com a subjetividade e a saúde.

Estou tomando "subjetividade" e "processos de subjetivação" no sentido atribuído por Foucault (1990), e Guattari (1986), de processos de produção histórica, o que nos leva a pensar cada sujeito singular como sujeito coletivo de enunciação.

A metodologia adotada no período de 1992/ 1994 por nós, técnicos do Programa de Saúde do Trabalhador/SES/R\}, a da pesquisa -
1. Hospital geral de médio porte da rede pública de saúde. situado na cidade do Rio de faneiro. 
intervenção, esbarrou em dificuldades que, num primeiro momento, tematizei a partir da relação dos trabalhadores com o tempo no dia a dia do processo de trabalho hospitalar ${ }^{2}$. Os convites formulados à participação recebiam quase sempre como resposta a frase "gostaria muito, mas não tenho tempo". Em nossa passagem por aquele Hospital, estudado no período 1992/1994, buscávamos ser mais que turistas, mais que visitas de cerimônia. Era preciso que fossemos parceiros. Creio que chegamos a ser freqüentadores assíduos, visitas bem vindas, mas sempre visitas. Destas,

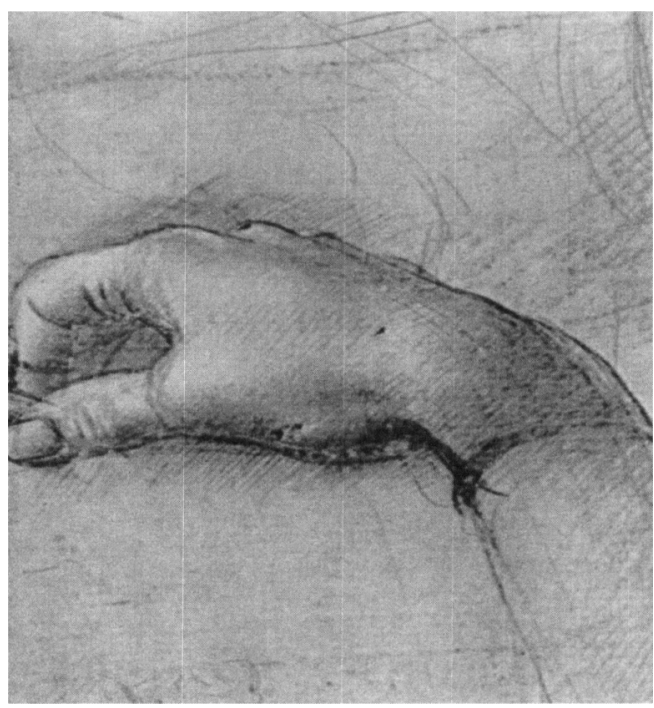

...segredo é mais dificil de levontar que o inconsciente.
Àquela época, as condições de estabelecimento do trabalho de pesquisa, nossas inserçöes em organismos de fiscalização da Secretaria Estadual de Saúde e em organismos acadêmicos de ensino e pesquisa - nossa implicação - foram insuficientemente analisadas. $O$ conceito de implicação é elaborado a partir da preocupação dos socioanalistas franceses (Lourau, 1979) com as relaçōes que se estabelecem nas relaçôes de intervenção institucional entre observador e observado. Há que se analisar o contexto em que uma demanda de análise e intervenção é apresentada a um profissional; como o analista está situado em relação ao grupo observado e seus diversos subgrupos; e que lugar o profissional ocupa nas relações sociais em geral.

Teoria e prática são parte de uma mesma rede de acontecimentos, não se faz teoria para posteriormente aplicá-la à prática e posteriormente retornar a teoria. Em debate com Michel Foucault, Deleuze assim afirmava: A prática é um conjunto de transiçōes de um ponto teórico para outro, e a teoria uma transição de uma prática para outra. Nenhuma teoria pode se desenvolver sem encontrar uma espécie de parede, e é preciso a prática para atravessar a parede (Deleuze, 1976:14). Analisando o hospital, constato que a análise teórica é insuficiente, é necessário que se instaurem condiçöes para que os trabalhadores e clientes do hospital possam falar de sua própria vida, por sua própria conta. Concordo com o que diz Deleuze neste debate: o intelectual teórico deixou de ser uma consciência representante, nāo pode se arrogar o direito de representar aqueles que lutam não há representaçāo, há apenas açāo, ação de teoria, ação de prática em relações de transiçâo ou de rede (Deleuze,1976:15).

Desde a década de 70 , intelectuais afirmam que os movimentos e grupos sociais não precisam deles para saber, eles sabem de si e 
do mundo e dizem-no muito bem, mas existe um sistema de poder que barra e invalida este discurso e este saber. Entre estes autores cito Marilena Chauí (1982), que tem apontado para os efeitos de ocultação produzido pelos discursos competentes. Em Curar Adoecendo, eu relatava a freqüência com que ouvia que se eles, que sabem mais, não conseguem resolver, o que nós podemos fazer... (Silva, 1994)

No curso do trabalho desenvolvido em Curar Adoecendo (Silva, 1994) esbarrei em uma parede. Percebia que um manto de invisibilidades era estendido sobre as questōes que os trabalhadores se colocavam acerca do seu trabalho. Percebia que o segredo é mais diffil de levantar que o inconsciente (Foucault, no mesmo debate com Deleuze, acima citado, p.23). Esbarrei também nessa aparente resistência a propor mudanças, a participar (ou compartilhar?) da fabricação de novos caminhos.

Para enfrentar estes obstáculos, busco hoje passar a outro discurso, que não mais pretende, como em Curar Adoecendo, descrever coletivamente a rotina do trabalho de uma enfermaria e o que fazem os trabalhadores; propōe pesquisar a própria metodologia adequada a produzir, com os trabalhadores em saúde, as condiçōes de visibilidade de seu saber. Trata-se de possibilitar o discurso múltiplo sobre o hospital, o sistema público de saúde, a experiência de exercer esse tipo de atividade profissional, e muito mais que tem sido monopolizado por alguns setores sociais, tornando invisíveis outras falas.

\section{Especialismos e individualismos}

Desde a criação do hospital moderno (Foucault, 1977) instalou-se a hegemonia médica e movimentos de resistência a esta hegemonia, com a instalação de corporativismos vários. O hospital se organiza em serviços ou departamentos que preservam as identidades, aprisionam os profissionais em

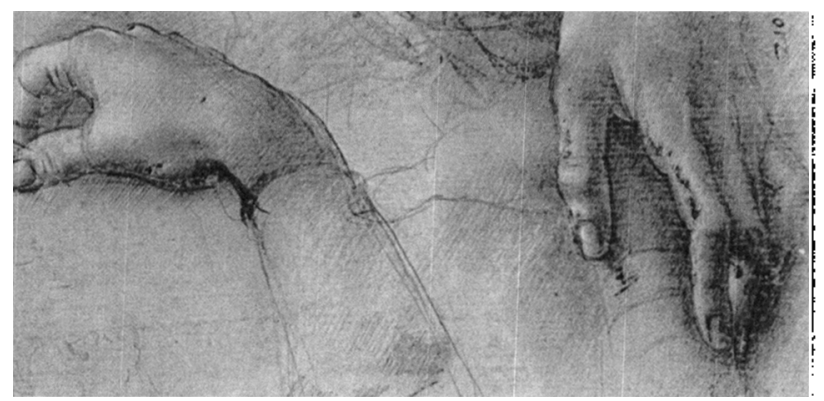

modelos e salas que acabam por serem verdadeiros mausoléus. $O$ processo de trabalho hospitalar, parcelado, reproduz as características da organização do trabalho industrial, e produz trabalhadores ora compromissados, ora desesperançados. $O$ tempo da vida e do sonho parece estar fora de seu alcance. O processo de trabalho, naturalizalizado como único possível, freqüentemente repete a lógica do trabalho taylorizado, por vezes ocultada pelo discurso valorativo do "trabalho em equipe". O corporativismo - expresso na competição entre as diversas profissōes presentes - e o individualismo constituem-se em obstáculos importantes à invenção de novos caminhos (Silva, 1994). Sabemos que, na organização taylorizada, não está em cena apenas a ação mecânica dos trabalhadores, sua atividade mental e inventividade é dificultada mas necessária à própria execução para que se possa chegar ao resultado pretendido. ${ }^{3}$ Onde, no hospital, se esconde tal inventividade? Como potencializá-la?

Os trabalhadores da saúde têm feito alguns movimentos de busca de uma nova forma de organizaçăo, que rompa com a atual paralisação das potências percebidas, em alguns momentos e por alguns trabalhadores, como existentes. Muitos desejam a criação de espaços/tempos de encontros transdisciplinares, potencializadores da diversidade de olhares presentes no hospital, mas o medo de uns de ficar irremediavelmente submetidos ao poder médico,
2-No trabalho taylorizado que encontramos no hospital, o tempo esta fora do campo de inventividade e autonomia dos trabalhadores, estes nâo tém o controle do rimo de trabalho nem mesmo de seus ritmos corporals.

3 - No trabalho hospitalar encontramos uma parti. cularidade, entre outras, o trabalho prescrito $e$ menos taylorizado que o trabalho real; os culdados aos pactentes. prescritos para ser emprestados de forma individualizada, eram organizados "em série" pelo pessoal de enfermagem, "dievido aj falta de tempo". 
e o medo de outros de perder todo o poder que têm, faz com que nada mude.

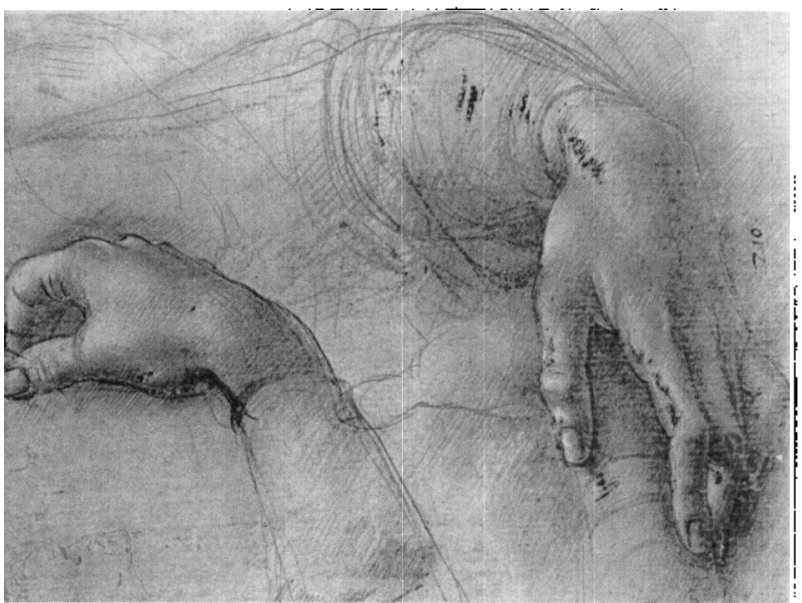

A atual divisăo do trabalho cria obstáculos ao bom atendimento e insatisfaçōes entre os trabalhadores. Esta divisāo está estabelecida entre profissionais de diferentes categorias profissionais, mas também entre trabalhadores de uma mesma categoria ou setor de trabalho. Algumas especialidades médicas são mais prestigiadas que outras. A distribuição das tarefas parceladas até o absurdo cria dificuldades de comunicação e realização dos objetivos manifestos de um hospital - cuidar da saúde de sua clientela.

No estudo de caso em que referencio estas notas (Silva,1994), observei efeitos desconcertantes do parcelamento das tarefas a que me refiro. Num certo dia foi relatado que eventualmente pacientes sumiam de seus leitos. Naquela semana havia ocorrido que, na hora da visita, familiares procuravam por uma dada paciente. O leito estava vazio e os familiares muito assustados. Onde estava a senhora que deveria estar deitada ali? Questionados, os auxiliares de enfermagem não sabiam informar. Nas papeletas dos doentes não havia nada, no livro de ocorrências também não. Após algum tempo de busca de explicações, estas foram obtidas havia sido transferida para uma enfermaria da

ala cirúrgica. Alívio geral e imediato esquecimento do incidente...

O Serviço de Enfermagem aponta a fragmentaçăo do trabalho como origem de outras insatisfaçōes: "ninguém pede a uma Nutricionista que empurre o carrinho de comida; na Enfermagem nunca está claro o que é papel do profissional porque existe o trabalho desqualificado, o excesso de divisão de tarefas". O que não é reconhecido é que se ninguém tem como formaçāo profissional "empurrar carrinho de comida", năo exige conhecimentos sofisticados e específicos, qualquer membro da equipe poderia fazê-lo! No entanto, não surge da enfermagem mais do que a queixa de uma situação a que parece estar grudada.

Observamos muitas desigualdades (nāo são apenas diferenças) produzidas pela divisâo do trabalho e, como outra face deste prisma, o impedimento à solidariedade.

A rotina de plantões é claramente produtora de sofrimento; seria mesmo necessário que tantos trabalhem nesse regime? Outras rotinas são feitas para dar errado, para tazer sumir paciente, para fazer sumir papel, para ninguém estar informado. Porque não sāo modificadas?

"Falta de comunicação" e "falta de tempo" são desculpas para tudo! A organização naturalizada do trabalho não tem sido posta em questăo. A distribuição das tarefas numa enfermaria hospitalar concentra-se na parte da manhã, deixando a tarde com um mínimo de trabalho prescrito e a noite num marasmo em que nem se pode dormir, nem há com que se ocupar. Quais as astúcias implicadas nesta organização de tarefas? E quais as cristalizaçōes que impedem a inventividade? Pela manhã, vêm os médicos, que devem encontrar seus pacientes limpos, sem cheiros, ter os diversos auxiliares à sua disposição. Também há, talvez, o desejo de acabar logo 
uma rotina entediante para poder conversar, nāo fazer nada, ou fazer algo não definido previamente.

Estudos acerca do tempo têm trazido contribuiçōes para problemática dos processos de subjetivação em relação com o trabalho. Comentávamos acima o quão os trabalhadores do hospital se mostram apressados. Na sociedade ocidental moderna o tempo tem sido gerenciado de forma a passar de um tempo corporal a um tempo ditado pela máquina, pelo tempo medido com precisão. Veschi afirma: Com isso surge a vivência da pressa (1996:15). O autor continua, dentro do mesmo tema - do tempo-máquina, comentando o tipo de relação que o trabalhador estabelece com seu trabalho:

Podemos fazer uma hipótese segundo a qualo fazer mais rápido é também fazer menos da coisa, deixar-se envolver menos por ela. Abre-se assim, um vazio cada vez mais amplo onde se procura fazer com que ele seja ocupado por "mais coisas", portanto em menos tempo...(Veschi,1996:15)

Dessa forma, haveria um pacto entre as exigências da produçâo na lógica taylorista, com as formas encontradas pelos trabalhadores na redução da angústia proveniente do trabalho insatisfatório, pelo menor envolvimento e menor investimento afetivo nas atividades.

O menor envolvimento com o trabalho faz parte de uma relaçāo de menor vivência de responsabilidade.

A introdução do tempo medido é análoga à introduçẫo do sentimento de culpa: produzem um alivio ambiguo no contexto em que se inserem. Graças ao sentimento de culpa a cultura cristã criou o perdão, sendo este, de certa forma, um grande alívio: evita-se a densidade da vivência que poderíamos designar como "responsabilidade", ou ainda, "ética". (Veschi,1996:17)
As responsabilidades, que penso serem coletivas, são freqüentemente atribuidas a outro trabalhador ou grupo, transformadas em culpa, o que levaria aos temas do individualismo e do corporativismo, de que tratei brevemente aqui.

Existem pistas de alguns outros movimentos e obstáculos que extrapolam os limites espaço-temporais do hospital, mas inegavelmente fazem parte do processo de trabalho ai desenvolvido. Sabe-se, a partir dos estudos de Marisa Palácios Rego, que as mulheres, em especial as casadas, referem sofrimento psíquico com maior frequeencia que os homens. De acordo com estes estudos, a metade dos trabalhadores do Hospital estudado no período 1992/1994 tinha outro emprego e mais da metade trabalhava mais de 40 horas semanais.

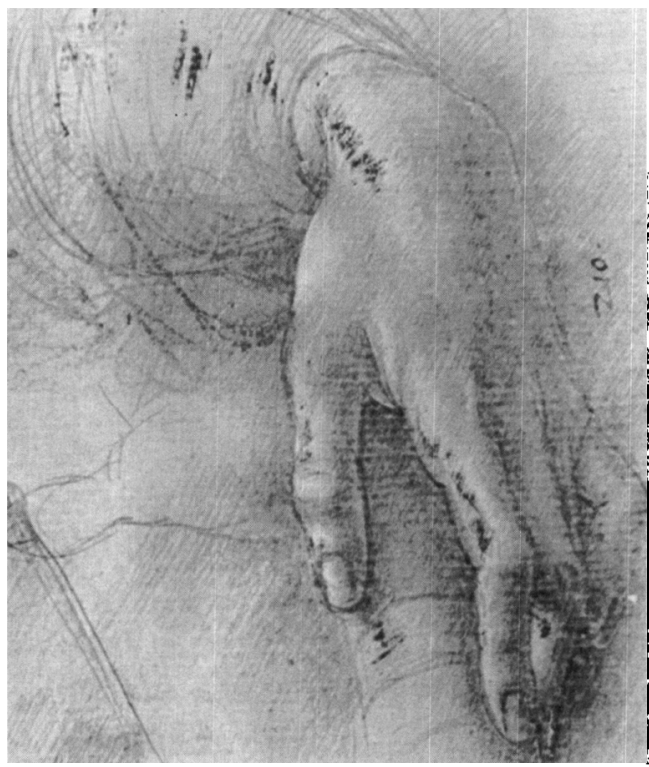

No sociedade ocidental moderna o tempotem sido gerenclado de forma a passar de um tempo corporal a um tempo ditodo pela móquina, pelo tempo medico comprecisóo.

No cotidiano a que tive acesso em meu estudo, as limitaçóes salariais eram pouco comentadas; eram mais freqüentes as referências às condiçōes gerais de trabalho, às relaçōes intra ou inter-equipes, às relaçôes com os pacientes e suas famílias, aos sentimentos que estas condiçōes e relaçōes suscitam. 
A organização do trabalho que fragmenta as tarefas e os trabalhadores, as caraterísticas da subjetividade moderna, individualista, atravessando a rede de relaçóes no hospital, a subjetividade produzida no Brasil desde os anos 60/70, anos autoritários e desqualificadores dos movimentos sociais (Coimbra,1992), exigem mais que mudanças conjunturais para seu enfrentamento. Comentando o Discours de La Boétie, Pierre Clastres diz que a instalação da tirania no lugar da liberdade exclui a lembrança da liberdade e, por conseguinte, o desejo de reconquistála. Toda sociedade dividida, entre tirano e

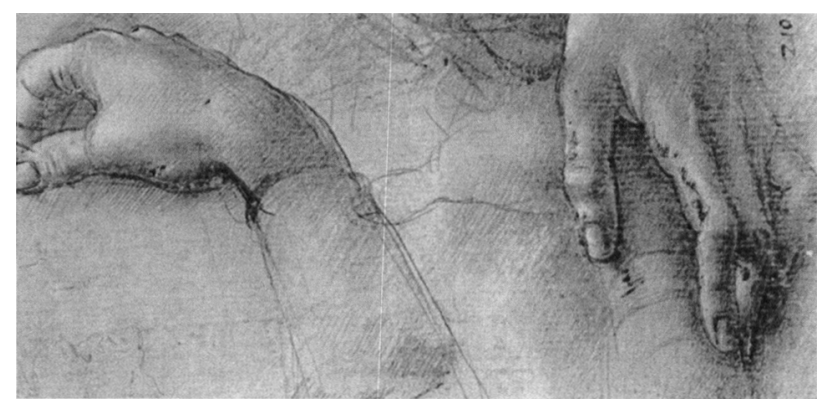

súditos, está portanto fadada a durar (La Boétie, 1982:122). No hospital, em que se diz que eles devem decidir, espera-se voluntariamente pela tutela dos tiranos, dos que sabem ou deveriam saber para dizer-nos o que fazer.

La Boétie nos fala da relação com a lei numa sociedade dividida:

Exclusives a qualquer liberdade, elas ditam a lei nova que regem a sociedade: deve-se amar o tirano. A insuficiência de amor é a transgressão da lei. Cada um vela pelo respeito à lei, cada um só avalia o próximo por sua fidelidade à lei. O amor à lei-o medo da liberdade - faz de cada um dos súditos um cúmplice do Príncipe: a obediência ao tirano exclui a amizade entre os súditos. (La Boétie, 1982:122)

Os trabalhadores do hospital queixam-se da falta de cumprimento da lei e pedem por leis novas e melhores, soluções administrativas, para suas insatisfaçōes. E queixam-se também da falta de solidariedade, de trabalho coeso, compartilhado.

Encontramos, nesse trecho escrito por Gilles Deleuze (1974:131), a nossa principal inquietação: como um grupo pode conduzir seu próprio desejo, colocá-lo em conexảo com os desejos de outros grupos e os desejos de massa, produzir os enunciados criadores correspondentes e constituir as condiçōes, não de sua unificação, mas de uma multiplicação propicia a enunciados de ruptura?

$\mathrm{Na}$ conclusão de Curar Adoecendo (Silva,1994), eu afirmava: Dizemos hoje que a esperança no Hospital năo está morta, mas está abafada. O medo e o cansaço tem produzido movimentos que interrompem os fluxos de solidariedade e inventividade. Mas, que medos? Que cansaços? E, principalmente, em que fluxos de solidariedade $e$ inventividade podemos embarcar? Naquele momento nāo foi possível deslizar na problematização que essas questóes sugerem. Pude apenas divisar pontas de sonhos, de proposiçōes criativas para a gestão e a organizaçăo do trabalho no hospital, ficando sempre com a dúvida se divisava meus próprios sonhos ou aqueles dos trabalhadores do hospital estudado.

Nos movimentos cartografados em Curar Adoecendo (Silva, 1994), as possíveis artes da existência (Foucault, 1977), fluxos plenos de inventividade e vida, pareciam estar freqüentemente abafadas. Se era possivel falar numa estética, esta estaria ligada ao "bom atendimento do paciente", noção que ora priorizava a ciência e a técnica, ora o tratamento humano, atencioso, capaz de dar suporte às angústias e dores do doente e sua família. Sempre que ocorre, este "bom atendimento" é fruto de encontros felizes entre muitas pessoas e coisas. São esses encontros felizes que animam a seguir buscando e potencializando as possibilidades, 
insistindo em cartografar movimentos de invenção de modos de trabalhar, de cuidar do cliente e de nós mesmos, trabalhadores em saúde, para assim, fazê-los mais intensos e freqüentes.

Observo no hospital geral uma estética do bom atendimento. Mas o que é bom atendimento para os diversos grupos envolvidos nessa teia de relaçōes? Do ponto de vista destes sujeitos, quais são os encontros felizes e os acontecimentos desejados? Destes, quais tem encontrado condiçōes de possibilidade? Quais as invisibilidades sobre as quais podemos e devemos lançar focos de luz? Estas perguntas têm nos servido de bússola em nossos encontros com o hospital geral e seus trabalhadores.

Claudia Osbrio da Silva Rua Barâo de itapagipe, 385 Błoco 02 Apt 303 , Tituca. Rio de Janeiro, Ri. Brasil. CEP: 20267-000.

Athayde, M. (1996). Ceståo de Coletivos de Trabalhoe Modemidade. Questües para a Engenharia de Prodkłçäo. Tese de Doutorado, COPPE/ UFR, R'o de janeiro.

Chauí, M. (1982). Cultura e Democracia: o discurso competente e outras falas. Sio Paulo: Ed. Moderna.

Coimbsa, C.M. B. (1992).Cerentes da ondem: agumas práticas psi nos anos 70 no Brasil, Tese de Doutorado, USP, Săo Pauto.

Dejours, C., Abdoucheli, E. \& layet, C. (1994). Psicodinâmica do Trabalho. São Paulo: Atlas.

Deleuze, G. \& Foucault, M. (1976). Os Intelectuais e o Poder. Em Capitalismo e Esquizofrenia - dossier Anti-Édipo (pp. 13-27). Lisboa: Asśrio e Alvim.

Deleuze, G. (1974). Très Problemas de Grupo. Em Escobar, C. H. (Org.). Psicanálise e Ciência da Históña (pp.125-138). Rio de Janeiro: Ed. Eldorado.

Foucault, M. (1989). Microfisica do Poder, Rio de Janeiro: Graal.

Foucault, M. (1990), OUso dos Prazeres - História da Sexualidade if. Rio de Janeiro: Editora Crazl.

Foucault, M. (1977). O Nascimento da Clinica. Rio de laneiro: ForenseUniversitária.

Guattari, F. \& Rodnik, S. (1986). Micropolitica: Cartografias do Desejo. Petrópolis: Vozes.

Guattari, F (1990). As Três Ecologias. Campina: Papins.

Cuattari, F. 11992). Fundamentos Ético-Políticos da Interdiscipdinariedade. Rev. Tempo Brasileiro, 108, $19-26$.
La Boétie, E. (1982). Discurso da Servidảo Voluntária. Săo Paulo: Brasiliense.

Laurell, A. C. \& Noriega, M. (1989). Processo de Produçăo e Saúde. Sāo Paulo: Hucitec.

Lourau, R. (1975)). A análise institucional. Petrópolis: Vozes.

Lourau, R. (1979). Sociólogo em Tempo Inteiro. Lisboa: Editoriał Estampa.

Oddone, l. et all (1986). Ambiente e Trabalihor a iuta dos trabalhadores pela saúde. São Páulo: Hucitec.

Pebthart, P.P. (1993). ANau do Tempo-Rei - 7 Ensaios sobre o Tempo da Loucura. Rio de Janeiro: Imago.

Pitta, A, M. F. (1989), Jrabalho Hospitalar e Soffimento Asiquico. Tese de Doutorado, USP, São Paulo.

Rego, M. P. (1993). Trabalho Hospitalar e Saúde Mental - O Caso de um Hospital Ceral e Público no Municipio do Rio de Janeiro. Dissertação de Mestrado, IMSAUERJ, Rio de Janeiro.

Rołnik, S. (1989). Cartografia Sentimental: transformaçסes contempoxảneas do desejo. São Paulo: Estaçẫo Libendade.

Silva, C. O. \& Athayde, M. (1992). Psicologia e Saúde ou Identidade eMultiplikidade. Revista do Departamento de fsicologia da UfF, vol:g, Rio de laneiro.

Sika, C. O. (1994). Curar Adbecendo - um esucudo em busca da saúde da inventividade e da vida. Dissertaçăo de Mestrado, CESTEH/ENSP/ FHCRUZ, Rio de Janeiro

Veschi, J. L. (1996). Nas espumas do tempo. Rio de Janeiro: Butiá. 